\title{
Mechanism of Vanadium-Catalyzed Deoxydehydration of Vicinal Diols: Spin-Crossover-Involved Processes
}

\author{
Yuan-Ye Jiang, ${ }^{\dagger, *}$ Ju-Long Jiang, ${ }^{\dagger}$ and Yao $\mathrm{Fu}^{\dagger, *}$ \\ ${ }^{\dagger}$ Hefei National Laboratory for Physical Sciences at the Microscale, iChEM, CAS Key Laboratory of \\ Urban Pollutant Conversion, Anhui Province Key Laboratory of Biomass Clean Energy, Department \\ of Chemistry, University of Science and Technology of China, Hefei 230026, People's Republic of \\ China \\ ${ }^{\star}$ School of Chemistry and Chemical Engineering, Qufu Normal University, Qufu 273165, People's \\ Republic of China
}




\section{Table of Contents}

V-catalyzed DODH starting by activating the secondary hydroxyl group of diols.......... S3

Less favored pathways of the extrusion of olefin from the vanadium(III) diolate 7-s ..... S4

Less favored pathways for the extrusion of olefin from the vanadium(III) diolate 30-s.. S5

Condensation of vicinal diols on (dipic) $\mathrm{VO}^{-}$starting by activating the secondary hydroxyl

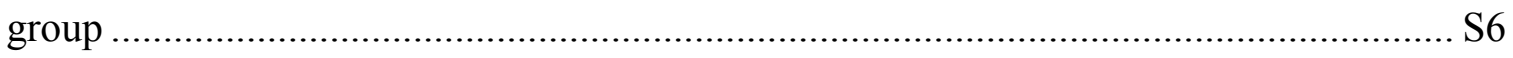

Condensation of vicinal diols on (dipic) $\mathrm{V}(\mathrm{OH})_{2}{ }^{-}$starting by activating the primary

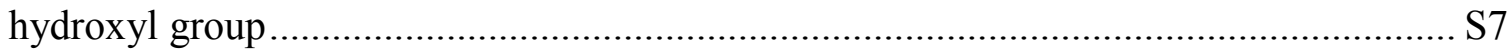

Relaxed potential energy scan of the $\mathrm{C}-\mathrm{O}$ bond distance of 10-t ................................... S8

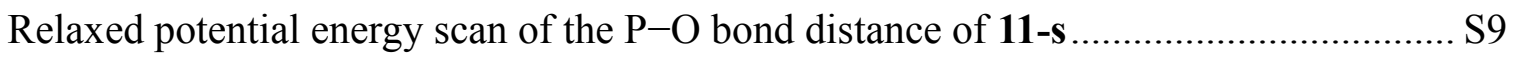


Scheme S1. Calculated free energy profiles of V-catalyzed DODH starting by activating the secondary hydroxyl group of vicinal diols in the condensation stage (in $\mathrm{kcal} / \mathrm{mol}$ ). (a) The condensation of vicinal diols and the reduction of vanadium( $\mathrm{V}$ ) diolate by $\mathrm{PPh}_{3}$. (b) The dominant pathway of the extrusion of olefin

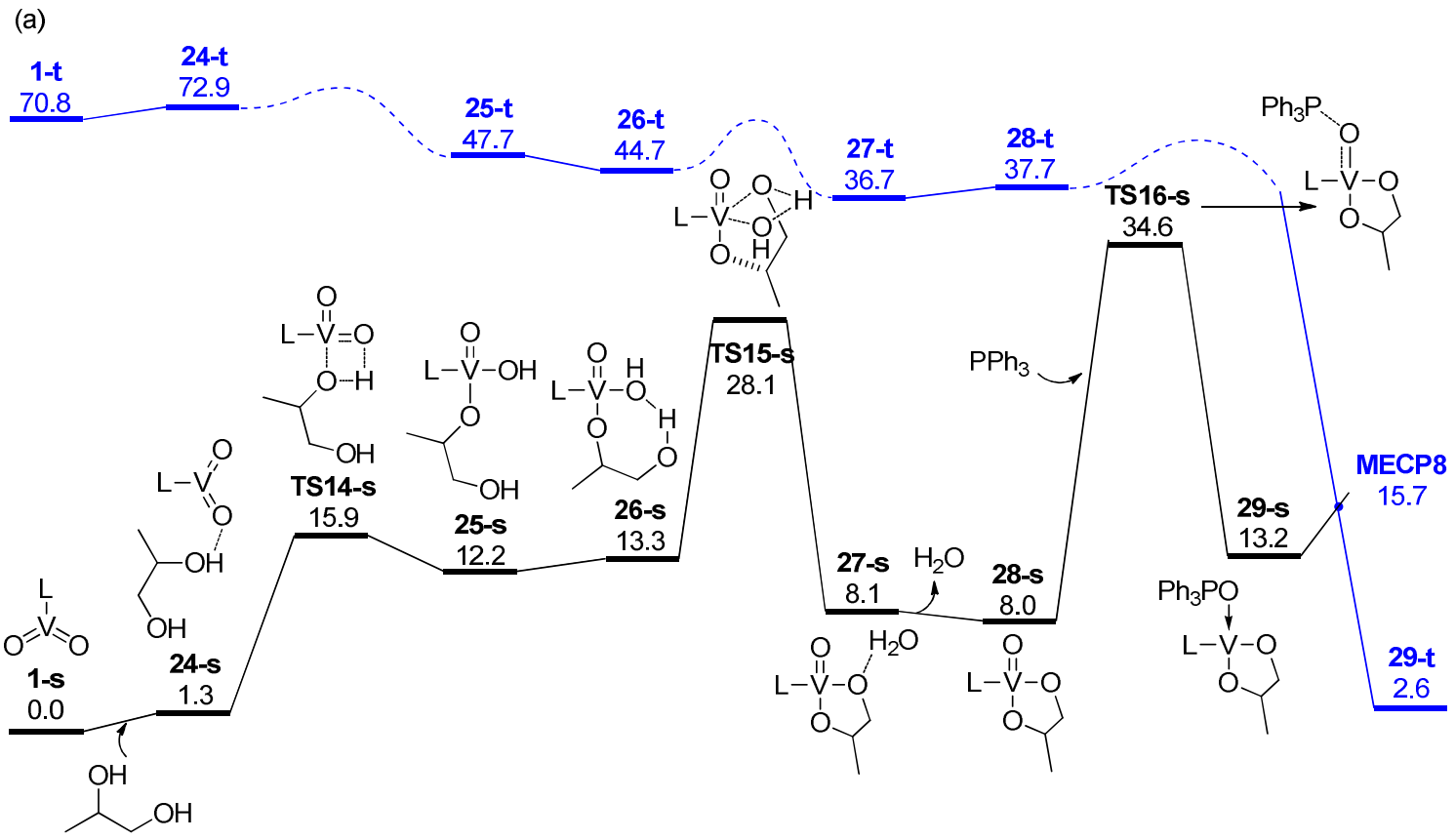

(b)

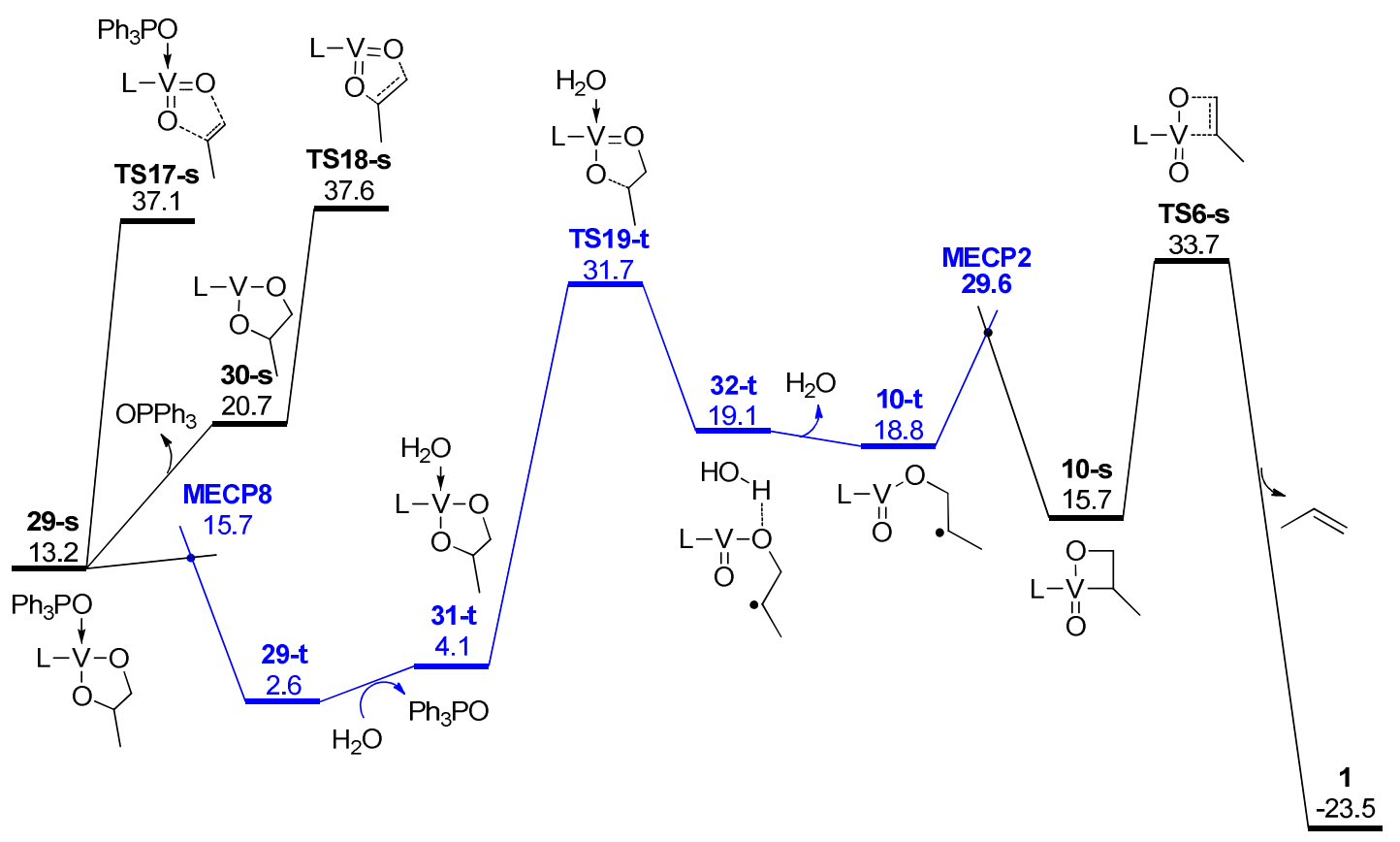


Scheme S2. Calculated free energy profiles of less favored pathways of the extrusion of olefin from the vanadium(III) diolate 7 -s and its derivatives (in $\mathrm{kcal} / \mathrm{mol}$ ). (a) $\mathrm{H}_{2} \mathrm{O}$-participated concerted mechanism. (b) $\mathrm{OPPh}_{3}$-participated stepwise mechanism starting by $\mathrm{C}-\mathrm{O}_{\text {axial }}$ bond cleavage. (c) $\mathrm{H}_{2} \mathrm{O}$-participated stepwise mechanism (d) The stepwise mechanism in the absence of $\mathrm{OPPh}_{3}$ and $\mathrm{H}_{2} \mathrm{O}$

(a)

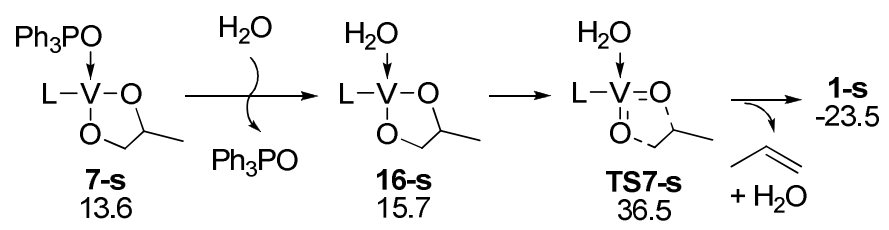

(b)

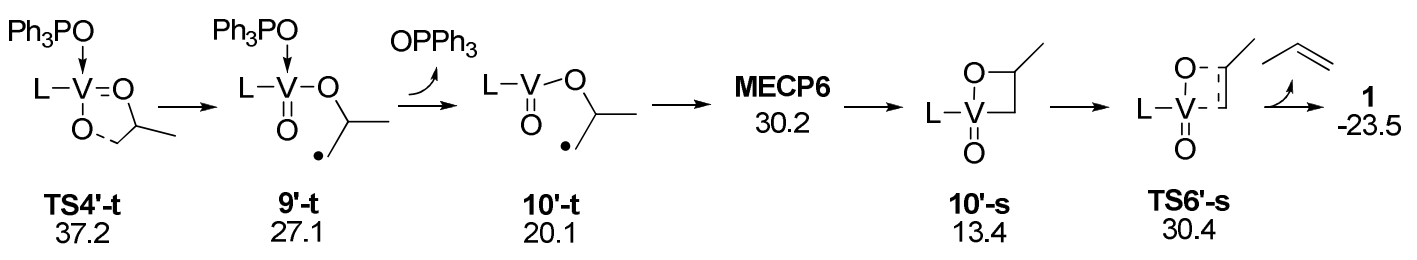

(c)

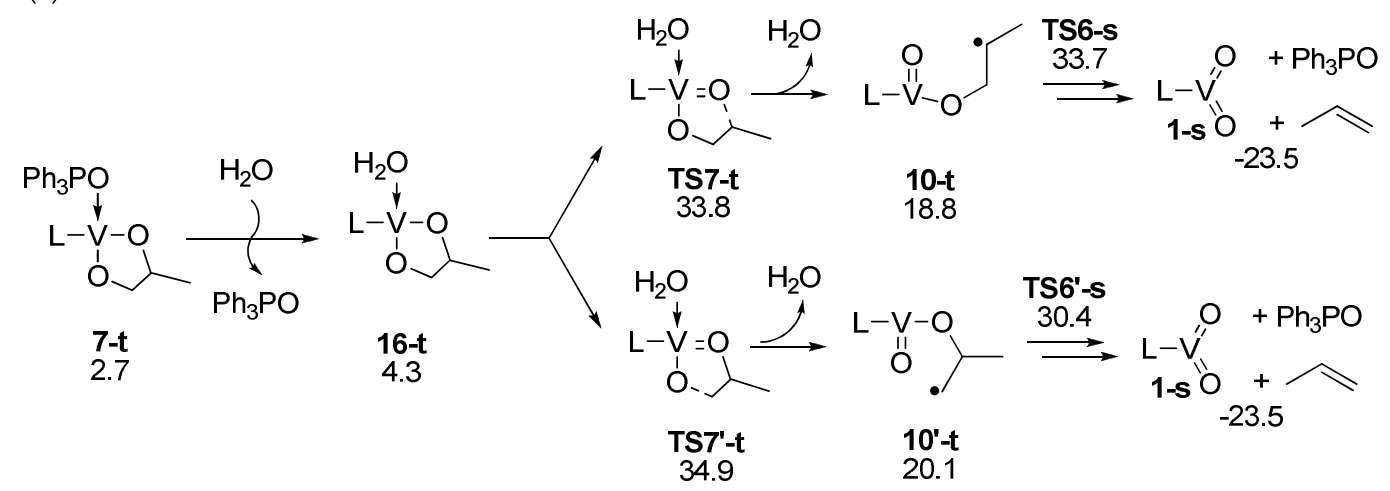

(d)

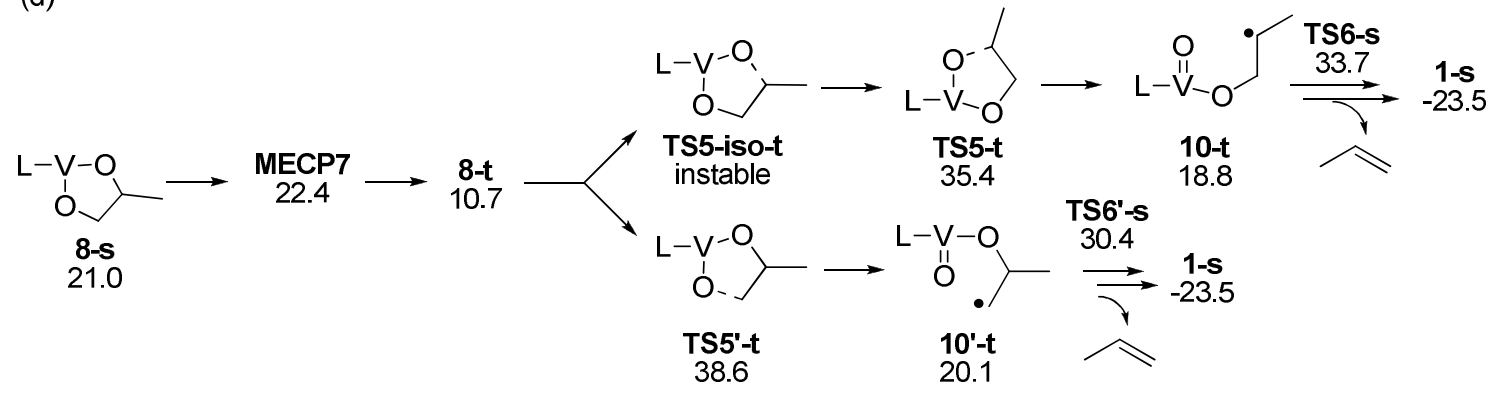


Scheme S3. Calculated free energy profiles of less favored pathways for the extrusion of olefin from the vanadium(III) diolate 30 -s and its derivatives (in $\mathrm{kcal} / \mathrm{mol}$ ). (a) $\mathrm{OPPh}_{3}$-participated stepwise mechanisms (b) $\mathrm{H}_{2} \mathrm{O}$-participated concerted mechanism. (c) $\mathrm{H}_{2} \mathrm{O}$-participated stepwise mechanism. (d) Stepwise mechanisms in the absence of $\mathrm{OPPh}_{3}$ and $\mathrm{H}_{2} \mathrm{O}$

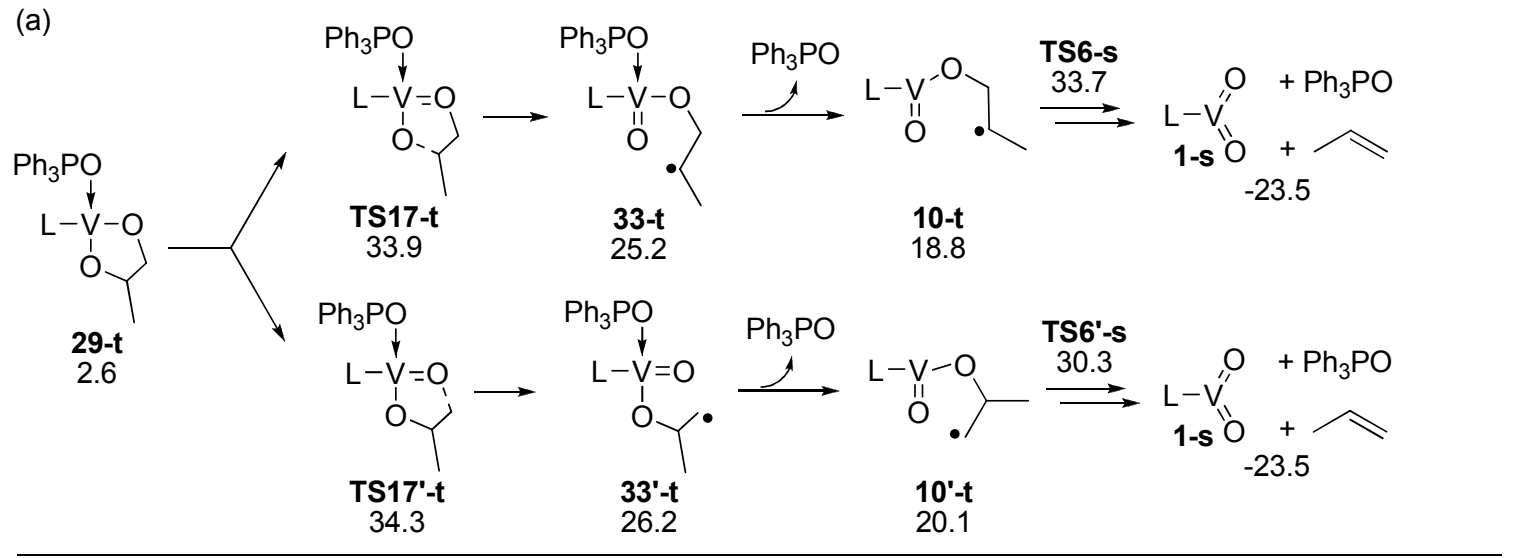

(b)

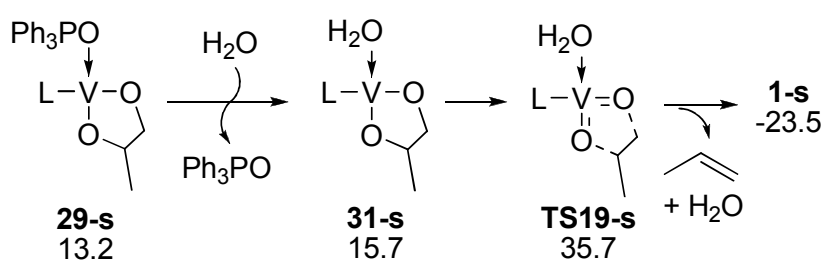

(c)
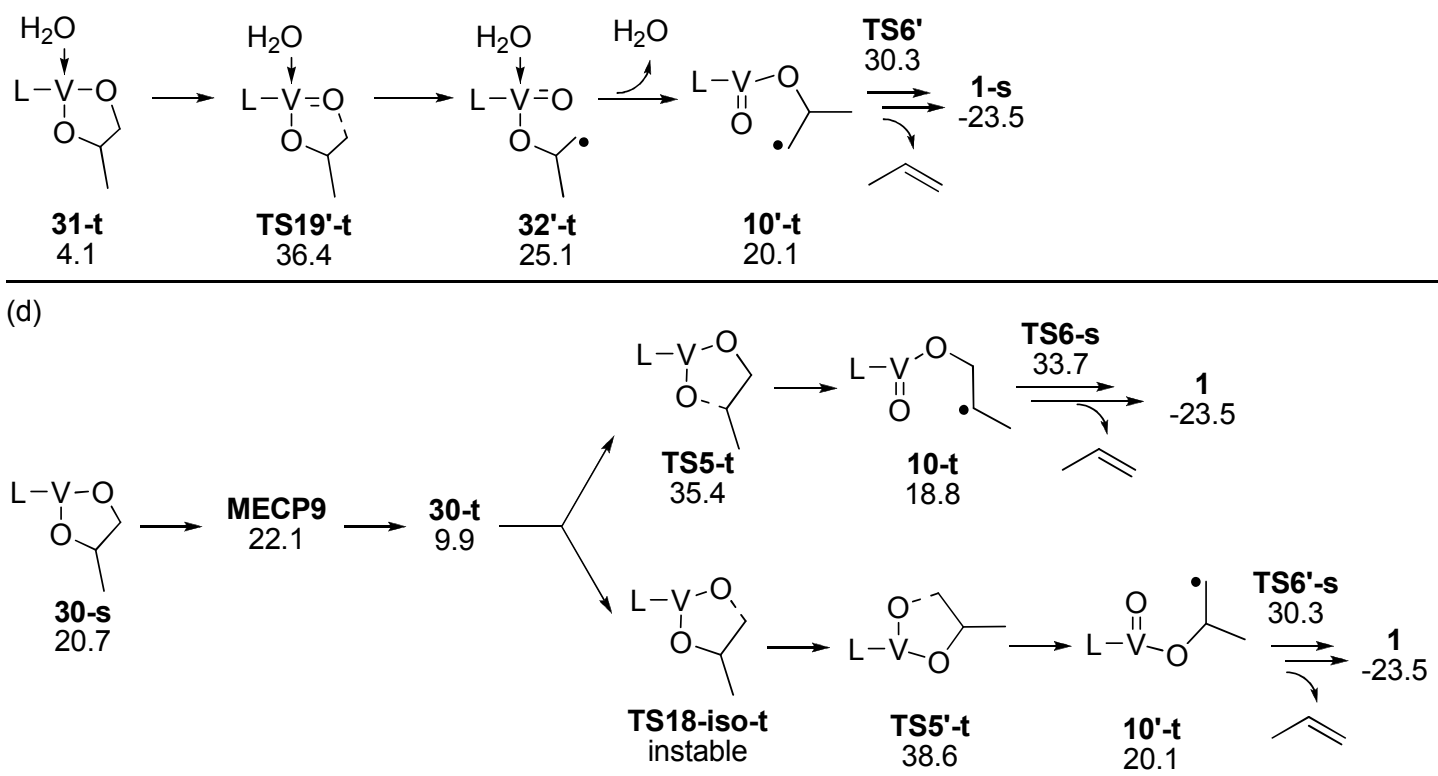
Scheme S4. Calculated free energy profiles of condensation of vicinal diols on (dipic) $\mathrm{VO}^{-}$starting by activating the secondary hydroxyl group (in $\mathrm{kcal} / \mathrm{mol}$ )

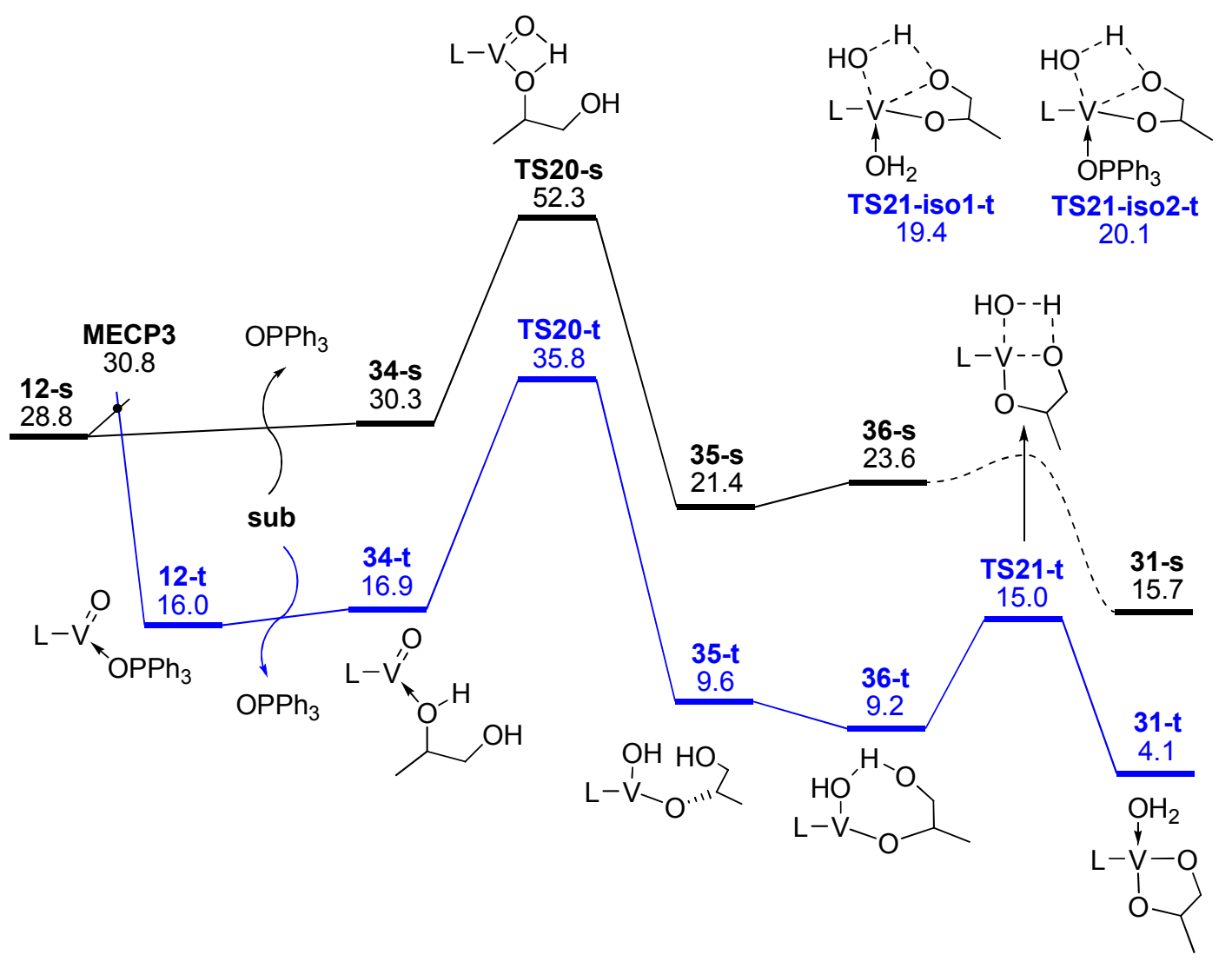


Scheme S5. Calculated free energy profile of the condensation of vicinal diols on (dipic) $\mathrm{V}(\mathrm{OH})_{2}{ }^{-}$starting by activating the primary hydroxyl group (in $\mathrm{kcal} / \mathrm{mol}$ )

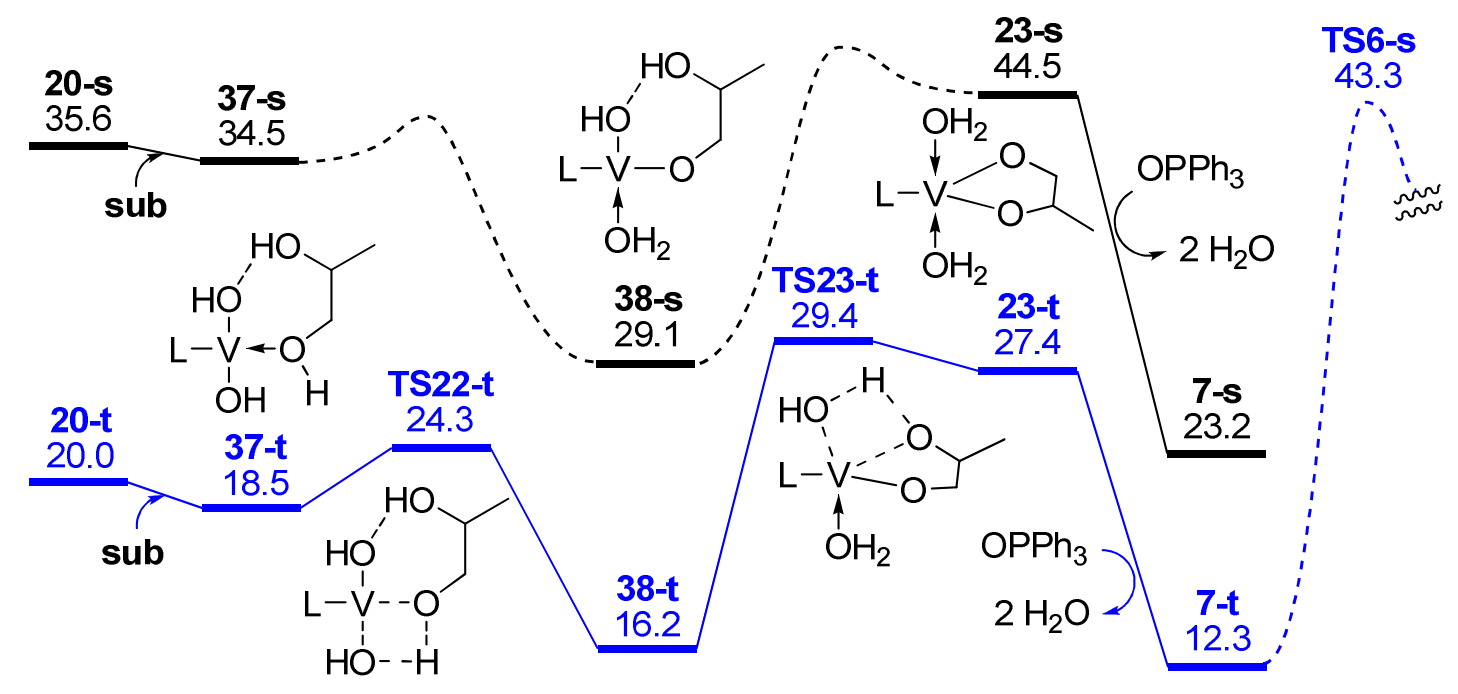




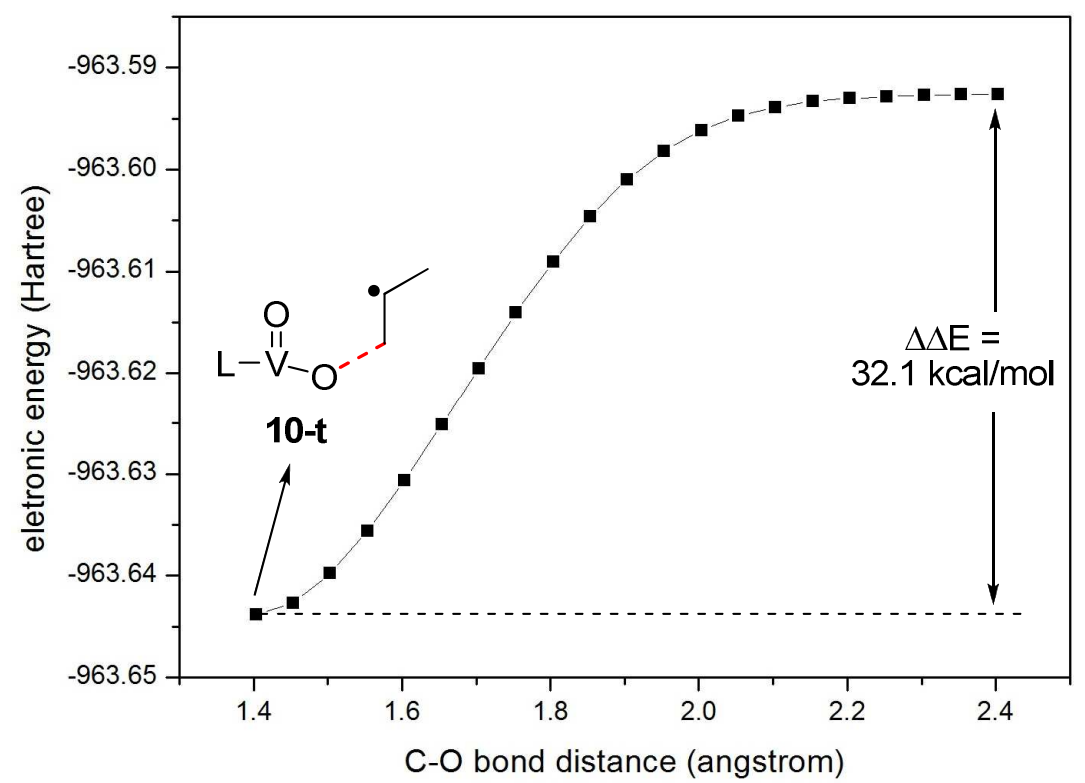

Figure S1. Relaxed potential energy scan of the $\mathrm{C}-\mathrm{O}$ bond distance of vanadium(IV) intermediate 10-t. 


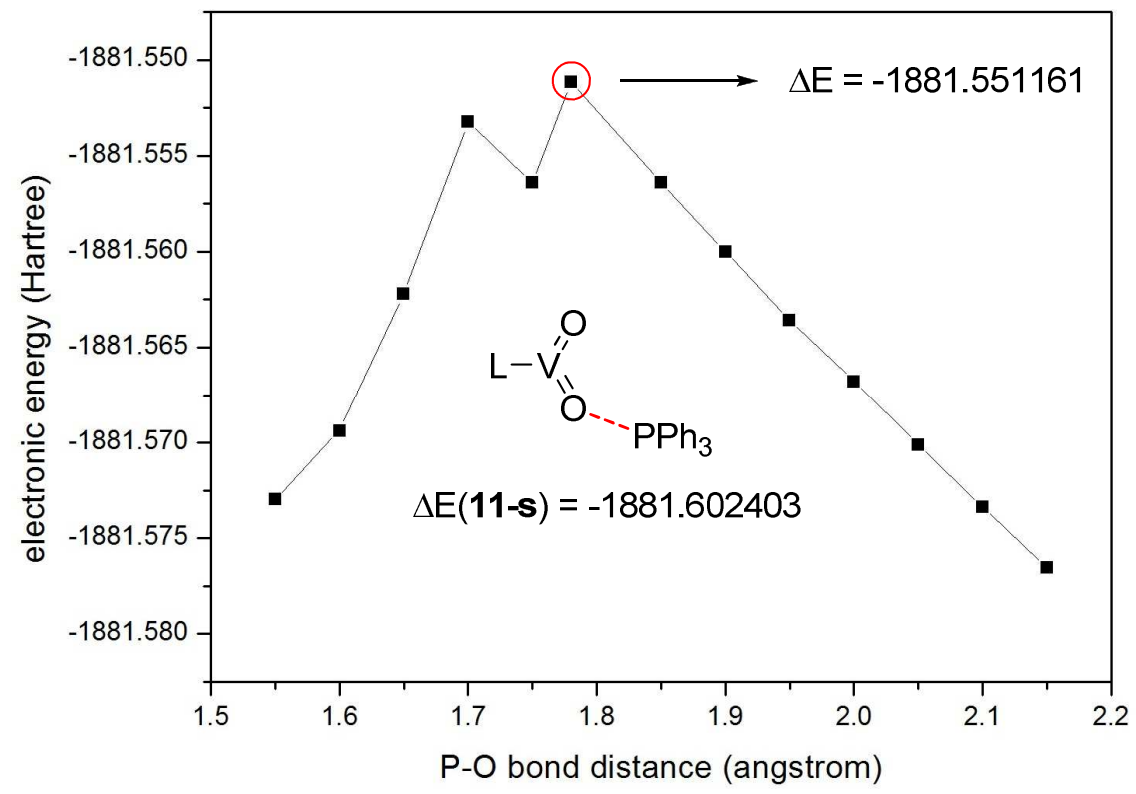

Figure S2. Relaxed potential energy scan of the $\mathrm{P}-\mathrm{O}$ bond distance of 11-s. 